\title{
Standardization for a Korean Version of the Speech, Spatial and Qualities of Hearing Scale: Study of Validity and Reliability
}

\author{
Bong Jik Kim ${ }^{1,2}$, Yong-Hwi An ${ }^{1,3}$, Jin-Woong Choi ${ }^{1,4}$, Moo Kyun Park ${ }^{1,5}$, \\ Joong Ho Ahn ${ }^{6}$, Seung Hwan Lee, Kyung Ho Park ${ }^{8}$, Byung Chul Cheon', \\ Byung Yoon Choi ${ }^{1,10}$, Yang-Sun Cho ${ }^{1,11}$, and Gyu Cheol Han ${ }^{1,12}$ \\ ${ }^{1}$ Questionnaire Translation Committee of the Korean Audiological Society, Seoul; and ${ }^{2}$ Department of Otolaryngology-Head and Neck \\ Surgery, College of Medicine, Dankook University, Cheonan; and ${ }^{3}$ Department of Otorhinolaryngology, Eulji Hospital, \\ College of Medicine, Eulji University, Seoul; and ${ }^{4}$ Department of Otolaryngology-Head and Neck Surgery, College of Medicine, \\ Chungnam National University, Daejeon; and Department of Otorhinolaryngology-Head and Neck Surgery, Seoul National University \\ Hospital, Seoul National University College of Medicine, Seoul; and ${ }^{6}$ Department of Otolaryngology, University of Ulsan College of \\ Medicine, Asan Medical Center, Seoul; and ${ }^{7}$ Department of Otolaryngology-Head and Neck Surgery, College of Medicine, Hanyang \\ University, Seoul; and ${ }^{8}$ Department of Otolaryngology-Head and Neck Surgery, The Catholic University of Korea College of Medicine, \\ Seoul; and ${ }^{9}$ Department of Preventive Medicine, Korea University College of Medicine, Seoul; and ${ }^{10}$ Department of Otorhinolaryngology, \\ Seoul National University Bundang Hospital, Seoul National University College of Medicine, Seongnam; and \\ ${ }^{I I}$ Department of Otorhinolaryngology-Head and Neck Surgery, Samsung Medical Center, Sungkyunkwan University School of Medicine, \\ Seoul; and ${ }^{12}$ Department of Otolaryngology-Head and Neck Surgery, Gachon University of Medicine \& Science, \\ Graduate School of Medicine, Incheon, Korea
}

\section{한국어판 The Speech, Spatial and Qualities of Hearing Scale의 표준화: 타당도 및 신뢰도 연구

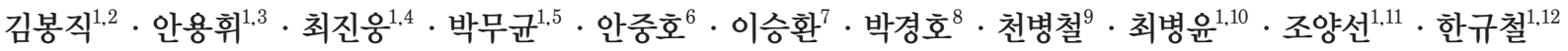 대한청각학회 설문지 번역위원회, ${ }^{1}$ 단국대학교 의과대학 이비인후과학교실, ${ }^{2}$ 을지대학교 의과대학 서울을지병원 이비인후과학교실, 충남대학교 의과대학 이비인후과학교실, ${ }^{4}$ 서울대학교 의과대학 서울대학교병원 이비인후과학교실, ${ }^{5}$ 울산대학교 의과대학 서울아산병원 이비인후과학교실, ${ }^{6}$ 한양대학교 의과대학 이비인후과학교실, ${ }^{7}$ 가톨릭대학교 의과대학 이비인후과학교실, ${ }^{8}$ 고려대학교 의과대학 예방의학교실, ${ }^{9}$ 서울대학교 의과대학 분당서울대학교병원 이비인후과학교실, ${ }^{10}$ 성균관대학교 의과대학 삼성서울병원 이비인후과학교실, ${ }^{11}$ 가천대학교 의과대학 이비인후과학교실}

Received December 19, 2016 Revised January 26, 2017 Accepted February 7, 2017 Address for correspondence Gyu Cheol Han, MD, PhD Department of OtolaryngologyHead and Neck Surgery,

Gachon University of Medicine \& Science, Graduate School of Medicine, 21 Namdong-daero 774beon-gil, Namdong-gu, Incheon 21565, Korea Tel +82-32-460-3324 Fax +82-32-467-9044 E-mail hangckr@gmail.com
Background and Objectives The Speech, Spatial and Qualities of Hearing Scale (SSQ) was designed to measure self-reported auditory disability in a wide variety of listening situations. Its 49 items cover many aspects of speech perception, spatial hearing, and qualities of hearing, which constitute the three parts of SSQ. However, there has been no reliable and valid Korean version of SSQ (K-SSQ), which made the measurement of auditory disability difficult. The aim of this study is to develop a K-SSQ and to determine its reliability and validity for clinical or academic use.

Subjects and Method An expert panel translated the original SSQ into Korean. A bilingual translator back-translated the translated version into English, which was then compared with the original version. After cognitive debriefing, K-SSQ was administered to 400 patients with hearing disability in 14 referral hospitals. Reliability was assessed using Cronbach's alpha coefficient and correlation study. Validity was evaluated by factor analysis and criterion validity based on the results of pure tone audiometry.

Results K-SSQ showed good reliability with high internal consistency (Cronbach's $\alpha=0.99$ ), and strong positive correlations across all three parts of SSQ. Construct validity was confirmed by the results of factor analysis and criterion validity demonstrated positive correlations between each part of SSQ and the results of pure tone audiometry.

Conclusion The K-SSQ is a reliable and valid tool for use as a behavioral measure of hearing ability in Korean-speaking patients, and it will provide a very useful evaluation tool for both clinicians and researchers. Korean J Otorhinolaryngol-Head Neck Surg 2017;60(6):279-94

Key Words Hearing disability $\cdot$ Quality $\cdot$ Questionnaire $\cdot$ Spatial $\cdot$ Standardization.

This is an Open Access article distributed under the terms of the Creative Commons Attribution Non-Commercial License (http://creativecommons.org/licenses/by-nc/4.0) which permits unrestricted non-commercial use, distribution, and reproduction in any medium, provided the original work is properly cited. 


\section{서 론}

The Speech, Spatial and Qualities of Hearing Scale(SSQ) 은 2004년 Gatehouse와 Noble에 의해 처음 도입되었다. SSQ 는 일상생활에서 경험하는 실제 대화에서 예상되는 여러 상 황에서의 청취 능력을 측정하기 위한 검사로, 단순 청력검사 에서는 측정할 수 없는 청취의 공간적, 질적 요소를 고려한다. 이러한 일상생활의 역동적 듣기 환경요소들을 감안하여 청취 능력을 평가함으로써 종합적인 청취의 장애 측정(disability assessment)을 가능하게 하는 검사이다.

SSQ는 'speech perception', 'spatial hearing, 'qualities of hearing'의 세 영역으로 이루어져 있다. 특히 양이 청(binaural hearing)을 평가할 수 있는 문항들이 다수 포함되어 있고, 이 러한 이유로 난청 환자에서 보청기나 인공와우를 이용한 청 력 재활 시 평가에 널리 이용되어 왔다. ${ }^{2,3)}$ 국내에서도 $\mathrm{SSQ}$ 를 이용하여 인공와우 아동들의 기능적 듣기 수행력을 평가하여 보고한 바 있다.")

$\mathrm{SSQ}$ 는 영어권에서 개발되어 사용되기 시작하였고, 시간이 지나며 러시아, 프랑스 등 여러 문화권에서 4 개 국어 이상으로 번역되고 검증되어 사용되고 있다. ${ }^{5,6}$ 또한 소아용, 부모용, 또 는 교사를 위한 SSQ 설문지 개발 등 그 적용 영역을 점차 넓 히고 있다." 설문지의 번역은 각국의 언어로 번역되는 과정에 서 각 문화권의 특성 및 언어적 특성을 고려한 검증이 동반되 어야 하는 보다 복잡하고 정교한 과정이다. 이러한 이유로 이 전에도 공신력이 있는 대한이과학회 설문지 번역위원회에서 중이 질환 및 난청에 관련된 설문지들을 번역하여 신뢰도와 타당도를 검증하였다. ${ }^{8-10}$

하지만, 아직까지 SSQ는 한국어로의 번역 및 검증이 제대 로 이루어지지 않아 한국인 대상의 연구에서 그 신뢰도와 타 당도를 확보하며 사용하는 데 어려움이 있다. 이러한 점에서 국제적인 학술지에 $\mathrm{SSQ}$ 를 이용한 연구를 발표하기에도 문제 가 있는 것이 사실이다. 대한청각학회 산하 설문지 위원회는 이러한 문제점을 해결하고자 $\mathrm{SSQ}$ 를 한국어로 번역하고, 그 신뢰도와 타당도를 검증하여 국내에서 난청 환자 대상의 평 가를 보다 객관화하고 그 결과를 임상연구에 활용할 수 있도 록 하고자 한다.

\section{대상 및 방법}

\section{번역 및 설문지 완성}

설문지의 선정 및 번역 과정, 검증 과정의 전반은 아래의 순서에 따라 이루어졌다.

\section{설문지 원본 획득 및 번역 허가}

위원회에서 전자우편으로 원저자인 William Noble을 접촉 하여 한국어판 번역에 대한 허가를 얻고 $\mathrm{SSQ}$ 의 원본을 제 공받았다.

$\mathrm{SSQ}$ 는 자기 기입식 설문지로 청력 자체의 측정을 위한 것이 아니라, 난청으로부터 발생할 수 있는 장애 즉 'auditory disability'를 평가하는 설문지이다. SSQ 설문지는 다양한 실제 일상 환경에서의 청취 능력을 평가할 수 있는 49개의 설문 문 항으로 이루어져 있다. 구체적으로 언어 청취(speech perception) 항목에 14문항, 공간 청취(spatial hearing) 항목에 17문 항, 음질 청취(qualities of hearing) 항목에 18문항이 속한다. 각 설문 항목은 시각 아날로그 척도(Visual Analogue Scale) 형식으로 이루어진 0 10까지 선택할 수 있는 선으로 구성되 어 있다. 선의 가장 좌측이 0으로 '전혀 아님(not at all)', 가장 우측이 10으로 '완벽하게 그러함(perfectly)'을 의미하며, 설문 대상자가 설문의 상황을 경험하지 못한 경우 '해당 없음(not applicable)'을 선택할 수 있게 하였다(Appendix).

\section{순 번역(Forward translation)}

대한청각학회 설문지 번역위원회에서 영어판 $\mathrm{SSQ}$ 의 순 번역 지침을 마련한 후, 2 인의 기획 위원이 각자 독립적으로 한국 어로 번역하였다. 각 설문 문항마다 문항을 설명할 수 있는 핵 심 단어(keyword)를 설정하였다.

\section{절충(Reconciliation)}

번역위원회에서 두 번역본을 검토하여 한국어 절충 번역본 을 만들었다. 절충의 일반적인 원칙들을 아래와 같이 정하며 회의를 진행하였다.

1) 빈번히 사용되는 특정 단어들을 한 단어로 통일하였다. 예) 영어 'you'에 해당하는 한국어는 '귀하'로 통일한다.

2) 설문지의 번역 시 원저자의 의도를 변경시키지 않는 범위 에서 직역보다는 현실에 맞게 의역하는 것을 원칙으로 한다.

3) 단어 사용 및 철자법의 확인을 위해서 네이버 사전(http:// dic.naver.com/)을 기준으로 사용한다.

\section{역 번역(Backward translation)}

한국어 절충 번역본을 영어와 한국어에 능통한 제 3 의 번역 자가 역 번역하였다. 그 후 위원회에서 설문지 원본과 역 번역 본을 비교 검토하였고, 원본의 핵심 단어가 역 번역한 문장에 $80 \%$ 이상 포함되어 있을 경우 번역이 제대로 된 것으로 평가 하였으며, 아닌 경우 재검토를 시행하였다. 재검토 후 새로 만 들어진 문장이 위원회에서 수용되면 이 과정은 완성되는 것으 로 결정하였다. 


\section{인지적 확인(Cognitive debriefing)}

단국대학교병원 이비인후과 외래 및 병동에서 난청을 호소 하는 환자 10 명에게 역 번역 과정까지 완성된 설문지를 이용 하여 설문을 시행하였다. 설문 응답의 소요 시간을 측정하고, 설문 문항 이해의 어려움 정도를 확인하였다. 수합된 결과를 바탕으로 이해가 힘든 부분은 설문 문항을 좀 더 용이하게 하 였고, 내용이 애매한 부분은 명확하게 정리하였다.

\section{감수 및 최종 교정}

완성된 역 번역본의 한국어 오류의 여부를 확인하기 위해 국어교육평가원에 감수를 의뢰하였고, 국어교육평가원의 검 증을 거쳐 최종 한국어 번역판(Korean version of the Speech, Spatial and Qualities of Hearing Scale, K-SSQ)을 완성하였 다(Appendix).

\section{대상자 선정}

대상자의 선정은 가천 의대 길병원, 가톨릭의대 서울성모병 원, 고려대학교 부속 구로병원, 단국대학교병원, 동아대학교 병원, 서울대학교병원, 분당서울대학교병원, 성균관의대 삼성 서울병원, 연세대학교 세브란스병원, 울산대학교 서울아산병 원, 을지대학교 서울 을지병원, 전남대학교병원, 충남대학교병 원 및 한양대학교 부속 구리병원 총 14 개의 병원(가나다순)에 서 난청을 가진 환자 중, 순음청력검사 결과가 있으면서 신뢰 도 검증을 위해 재방문이 가능한 환자를 대상으로 하였다. 연구에 참여한 모든 병원은 연구 전 각 병원의 임상연구윤리 위원회(IRB)의 심의를 받았다.

\section{신뢰도 및 타당도 조사}

최종 한국어판 SSQ 인쇄물과 설문작성을 위한 해설서를 연구에 참여한 병원에 우편으로 배포하고 설문지 위원회의 위원들이 각 병원의 담당자들에게 설문 내용 및 지침을 설명 하였다. 외래 및 병동의 환자들을 대상으로 연구 참여에 대 한 동의를 구한 후 설문지 작성 작업을 시행하였고, 환자 본인 이 설문지를 작성하는 것을 원칙으로 하되 이해가 되지 않는 문항에 대해서는 보호자와 같이 상의하여 설문을 작성하도 록 하였다.

\section{통계분석}

본 연구에서는 설문 결과를 평균, 표준편차 등의 기초 통계 량으로 요약하였다. 설문지 번역본의 신뢰도를 확인하기 위 하여 Cronbach $\alpha$ 값을 이용한 내적 일치도(internal consistency)와, 'speech perception', 'spatial hearing,' 'qualities of hearing' 각 파트 간의 상관계수를 추정하였다. 타당도의 검
증을 위해서는 구성개념 타당도(construct validity)와 준거 타당도(criterion validity)를 검증하였는데, 구성개념 타당도 의 확인을 위해서 요인 분석(factor analysis)을 실시하였고, 준거 타당도는 상관분석을 이용하여 순음청력검사를 기준으 로 3개의 파트 간 상관계수를 산출하였다. 통계분석은 SAS (9.2 version; SAS Institute Inc., Cary, NC, USA)를 이용하 여 이루어졌다.

\section{결 과}

\section{번역 및 설문지 완성}

최종 한국어판 $\mathrm{SSQ}$ 를 제작하였고, 설문지의 공식 명칭은 $\mathrm{K}-\mathrm{SSQ}$ 로 하였으며, 한글 명칭은 '언어 공간 음질 청취 평가' 로 결정하였다. 설문지의 마지막 부분에 청력검사 소견을 적 는 칸을 추가하고 설문의 조사자가 기입하게 하여 분석의 기 본 자료로 이용하였다.

10 명의 난청 환자를 대상으로 한 인지적 확인을 시행한 결 과 설문 응답에 걸린 시간은 평균 9.8 분이었고, 총 문항이 49 문항에 달해 10 분 이상 소요된 경우도 2예로 피험자로 하여 금 주의가 분산되지 않고 설문에 집중할 수 있는 환경을 만 들어 주는 것이 중요하다고 파악되었다. 피험자의 이해가 어 려웠던 문항에 대해서는 원저자에게 문항의 의미를 다시 확 인한 후 의미의 변화가 없는 범위에서 이해하기 쉽게 수정하 였다. 예를 들어 첫 번째 파트인 'speech hearing'의 8번째, 9 번째 설문 문항에서 'same pitch'를 10 명의 환자를 대상으로 한 파일럿 설문에서는 '같은 높이'로 표기했는데, 설문 결과 '같은 굵기(톤)'로 하는 것이 환자가 이해하기에 수월해 수정 하였다.

\section{대상자의 일반적 특성}

14 개의 기관에서 총 400 명의 환자가 설문에 답하였으며, 성 별이 확인된 경우 남자는 166 명, 여자는 199 명이었다. 평균 연 령은 남자 56.8세, 여자 55.6세였다.

\section{$\mathrm{K}-\mathrm{SSQ}$ 문항별 응답 및 청력 분포 요약}

본 연구에 포함된 400명에서 $\mathrm{K}-\mathrm{SSQ}$ 설문지의 문항별 응 답과 파트별 응답(해당 파트에 포함되는 문항들의 평균), 청 력의 분포를 요약하였다(Table 1). Speech perception의 평 균값은 6.0 이었고, spatial hearing의 평균값은 5.8이었으며, qualities of hearing의 평균값은 6.4 였고, 청력 값의 평균은 $38.6 \mathrm{~dB}$ 이었다. 
Table 1. Mean score of each SSQ item and hearing distribution

\begin{tabular}{|c|c|c|c|}
\hline Item & $n$ & Mean $\pm S D$ & Median (min, max) \\
\hline 1 & 376 & $5.9 \pm 2.7$ & $6(0,10)$ \\
\hline $1 \_2$ & 380 & $7.7 \pm 2.6$ & $8(0,10)$ \\
\hline $1 \_3$ & 380 & $6.8 \pm 2.8$ & $7(0,10)$ \\
\hline $1 \_4$ & 381 & $5.6 \pm 2.8$ & $5(0,10)$ \\
\hline $1 \_5$ & 376 & $5.9 \pm 2.7$ & $6(0,10)$ \\
\hline $1 \_6$ & 378 & $4.9 \pm 2.9$ & $5(0,10)$ \\
\hline $1 \_7$ & 368 & $5.6 \pm 2.9$ & $5(0,10)$ \\
\hline 1_8 & 382 & $6.3 \pm 2.7$ & $6(0,10)$ \\
\hline 1_9 & 381 & $6.4 \pm 2.7$ & $7(0,10)$ \\
\hline 1_10 & 384 & $5.2 \pm 2.9$ & $5(0,10)$ \\
\hline $1 \_11$ & 384 & $5.8 \pm 2.7$ & $6(0,10)$ \\
\hline 1_12 & 384 & $5.6 \pm 2.9$ & $6(0,10)$ \\
\hline 1_13 & 383 & $7.0 \pm 2.7$ & $8(0,10)$ \\
\hline 1_14 & 384 & $5.2 \pm 2.9$ & $5(0,10)$ \\
\hline $2 \_1$ & 367 & $5.8 \pm 2.9$ & $6(0,10)$ \\
\hline 2_2 & 379 & $5.9 \pm 2.9$ & $6(0,10)$ \\
\hline 2_3 & 381 & $6.5 \pm 2.9$ & $7(0,10)$ \\
\hline $2 \_4$ & 377 & $6.6 \pm 2.8$ & $7(0,10)$ \\
\hline $2 \_5$ & 373 & $5.8 \pm 2.9$ & $6(0,10)$ \\
\hline $2 \_6$ & 378 & $6.1 \pm 2.8$ & $6.5(0,10)$ \\
\hline 2_7 & 378 & $6.0 \pm 2.8$ & $6(0,10)$ \\
\hline 2_8 & 380 & $5.3 \pm 2.8$ & $5(0,10)$ \\
\hline 2_9 & 379 & $5.5 \pm 2.8$ & $6(0,10)$ \\
\hline $2 \_10$ & 374 & $5.4 \pm 2.9$ & $5(0,10)$ \\
\hline 2_11 & 378 & $5.3 \pm 2.9$ & $5(0,10)$ \\
\hline 2_12 & 379 & $5.9 \pm 3.0$ & $6(0,10)$ \\
\hline $2 \_13$ & 379 & $6.1 \pm 2.8$ & $6(0,10)$ \\
\hline 2_14 & 353 & $5.8 \pm 3.1$ & $6(0,10)$ \\
\hline $2 \_15$ & 360 & $5.6 \pm 2.8$ & $5(0,10)$ \\
\hline $2 \_16$ & 357 & $5.8 \pm 2.7$ & $5(0,10)$ \\
\hline $2 \_17$ & 377 & $5.7 \pm 2.8$ & $6(0,10)$ \\
\hline 3_1 & 374 & $6.0 \pm 2.9$ & $6(0,10)$ \\
\hline 3_2 & 357 & $6.3 \pm 2.9$ & $7(0,10)$ \\
\hline 3_3 & 376 & $6.4 \pm 2.8$ & $7(0,10)$ \\
\hline 3_4 & 377 & $6.9 \pm 2.6$ & $7(0,10)$ \\
\hline 3_5 & 364 & $7.0 \pm 2.7$ & $7(0,10)$ \\
\hline 3_6 & 379 & $7.3 \pm 2.7$ & $8(0,10)$ \\
\hline 3_7 & 366 & $6.6 \pm 2.9$ & $7(0,10)$ \\
\hline 3_8 & 381 & $6.7 \pm 2.8$ & $7(0,10)$ \\
\hline 3_9 & 382 & $6.7 \pm 2.7$ & $7(0,10)$ \\
\hline 3_10 & 381 & $6.7 \pm 2.7$ & $7(0,10)$ \\
\hline 3_11 & 374 & $6.4 \pm 2.9$ & $7(0,10)$ \\
\hline 3_12 & 377 & $7.1 \pm 2.6$ & $8(0,10)$ \\
\hline 3_13 & 380 & $7.1 \pm 2.7$ & $8(0,10)$ \\
\hline 3_14 & 377 & $5.2 \pm 3.1$ & $5(0,10)$ \\
\hline 3_15 & 376 & $5.2 \pm 3.1$ & $5(0,10)$ \\
\hline 3_16 & 331 & $5.9 \pm 2.9$ & $6(0,10)$ \\
\hline 3_17 & 372 & $6.2 \pm 2.9$ & $7(0,10)$ \\
\hline
\end{tabular}

Table 1. Mean score of each SSQ item and hearing distribution (Continued)

\begin{tabular}{|c|c|c|c|}
\hline Item & $n$ & Mean \pm SD & Median (min, max) \\
\hline 3_18 & 373 & $5.6 \pm 2.7$ & $5(0,10)$ \\
\hline Speech hearing* & 391 & $6.0 \pm 2.4$ & $6(0,10)$ \\
\hline Spatial hearing* & 391 & $5.8 \pm 2.5$ & $6.1(0,10)$ \\
\hline Qualities hearing* & 390 & $6.4 \pm 2.4$ & $6.7(0,10)$ \\
\hline $\begin{array}{l}\text { Pure tone } \\
\text { audiometry }\end{array}$ & 305 & $38.6 \pm 17.8$ & $38.1(2.5,106.3)$ \\
\hline \multicolumn{4}{|c|}{$\begin{array}{l}\text { *speech hearing: 1-1 1-14 평균, spatial hearing: 2-1 2-17 평 } \\
\text { 균, qualities hearing: 3-1 3-18 평균, +청력은 500, } 1000,2000,4000 \\
\mathrm{~Hz} \text { 값을 평균내서 사용, 보청기를 착용하지 않은 경우는 보청기 착용 전 } \\
\text { 양쪽 } 500,1000,2000,4000 \mathrm{~Hz} \text { 값들의 평균 사용, 보청기를 한 쪽만 착용 } \\
\text { 하였거나 양쪽 모두 착용한 경우 보청기 착용 후 양쪽 } 500,1000,2000 \\
4000 \mathrm{~Hz} \text { 값들의 평균 사용. SD: standard deviation, SSQ: the Speech } \\
\text { Spatial and Qualities of Hearing Scale }\end{array}$} \\
\hline
\end{tabular}

Table 2. Cronbach's alpha of each part comprising SSQ

\begin{tabular}{lc}
\hline \multicolumn{1}{c}{ Part } & Cronbach's alpha \\
\hline Speech hearing & 0.97 \\
Spatial hearing & 0.98 \\
Qualities hearing & 0.97 \\
\hline Total & 0.99
\end{tabular}

Adapted from https://en.wikipedia.org/wiki/Cronbach\%27s alpha. ${ }^{111} \alpha \geq 0.9$ excellent, $0.9>\alpha \geq 0.8$ good, $0.8>\alpha \geq 0.7$ acceptable, $0.7>\alpha \geq 0.6$ questionable, $0.6>\alpha \geq 0.5$ poor, $0.5>\alpha$ unacceptable. SSQ: the Speech, Spatial and Qualities of Hearing Scale

\section{신뢰도 분석}

\section{내적 일치도}

신뢰도는 결과치의 일관성을 나타내는 지표로서 SSQ 설문 지의 신뢰도 평가를 위해 모든 문항과 각 파트에 해당되는 문항들 내에서 Cronbach's alpha 값을 구하였다(Table 2). 모 든 문항에 대한 Cronbach's alpha 값은 0.99로 높은 내적 일 치도를 보였으며, 파트 중 speech hearing에 해당되는 문항 들에서는 0.97, spatial hearing에 해당되는 문항들에서는 0.98 , qualities hearing에 해당되는 문항들에서는 0.97 로 모든 파 트에서 높은 내적 일치도를 보였다.

\section{상관관계 분석}

$\mathrm{SSQ}$ 설문지의 신뢰도 평가를 위한 다른 방법으로 파트 간 Spearman correlation을 추정하였다. Speech perception과 spatial hearing 상관계수는 0.83( $p$ value $<0.0001)$, speech perception과 qualities of hearing 간 상관계수는 $0.87(p$ value $<$ 0.0001), spatial hearing과 qualities of hearing 간 상관계수 는 0.85 ( $p$ value< 0.0001$)$ 로 파트들 간에 강한 양의 상관관계 가 있는 것으로 추정되었다. 
Validity and Reliability Study of Korean-SSQ I Kim BJ, et al.

Table 3. Factor analysis results of SSQ questionnaire (based on factor loading of 0.4)

\begin{tabular}{|c|c|c|c|c|c|}
\hline Item & Factor 1 & Factor 2 & Factor 3 & Factor 4 & Factor 5 \\
\hline $2 \_4$ & 0.78141 & 0.33082 & 0.25427 & 0.19455 & 0.03563 \\
\hline $2 \_10$ & 0.77282 & 0.24279 & 0.28982 & 0.18578 & 0.25518 \\
\hline $2 \_6$ & 0.75293 & 0.29275 & 0.30289 & 0.23391 & 0.18771 \\
\hline $2 \_11$ & 0.74713 & 0.29748 & 0.29937 & 0.18742 & 0.27157 \\
\hline 2_9 & 0.72722 & 0.30033 & 0.33582 & 0.18261 & 0.31154 \\
\hline $2 \_17$ & 0.72719 & 0.3087 & 0.22946 & 0.18081 & 0.32082 \\
\hline $2 \_5$ & 0.72343 & 0.29601 & 0.39308 & 0.2559 & 0.10278 \\
\hline $2 \_8$ & 0.71346 & 0.3134 & 0.37808 & 0.18412 & 0.2997 \\
\hline 2_7 & 0.70968 & 0.3239 & 0.38219 & 0.19613 & 0.14177 \\
\hline $2 \_12$ & 0.69892 & 0.46818 & 0.28214 & 0.08757 & 0.26883 \\
\hline $2 \_2$ & 0.69225 & 0.29656 & 0.3859 & 0.22629 & 0.12763 \\
\hline $2 \_1$ & 0.66636 & 0.30414 & 0.47103 & 0.18466 & 0.06797 \\
\hline $2 \_13$ & 0.63311 & 0.52795 & 0.33598 & 0.00814 & 0.24416 \\
\hline 2_3 & 0.60835 & 0.54912 & 0.32097 & 0.07895 & 0.14527 \\
\hline 3_1 & 0.54847 & 0.51463 & 0.36565 & 0.12126 & 0.28196 \\
\hline 3_8 & 0.34981 & 0.73594 & 0.38628 & 0.17185 & 0.16539 \\
\hline 3_6 & 0.33308 & 0.72525 & 0.31026 & 0.11678 & 0.3088 \\
\hline 3_10 & 0.2611 & 0.72033 & 0.44495 & 0.22507 & 0.19341 \\
\hline 3_13 & 0.41194 & 0.71101 & 0.18407 & 0.19073 & 0.2116 \\
\hline 3_9 & 0.36655 & 0.71047 & 0.35525 & 0.20065 & 0.15681 \\
\hline 3_7 & 0.34189 & 0.70881 & 0.31928 & 0.1783 & 0.22184 \\
\hline 3_12 & 0.27203 & 0.70361 & 0.14858 & 0.29955 & 0.18511 \\
\hline 3_5 & 0.32864 & 0.70361 & 0.38148 & 0.08034 & 0.3282 \\
\hline 3_4 & 0.41733 & 0.66998 & 0.39101 & 0.11098 & 0.20339 \\
\hline 3_11 & 0.24318 & 0.6464 & 0.24912 & 0.25696 & 0.35548 \\
\hline 3_3 & 0.40862 & 0.62112 & 0.36365 & 0.21406 & 0.22483 \\
\hline 1_13 & 0.29239 & 0.60344 & 0.44895 & 0.27891 & 0.01211 \\
\hline 1_2 & 0.22002 & 0.56775 & 0.49954 & 0.03957 & 0.16183 \\
\hline 3_17 & 0.36232 & 0.5602 & 0.45422 & 0.35565 & 0.10748 \\
\hline 3_16 & 0.31905 & 0.50403 & 0.45717 & 0.44328 & 0.04859 \\
\hline $1 \_4$ & 0.36861 & 0.30643 & 0.76407 & 0.21884 & 0.07409 \\
\hline 1_1 & 0.25785 & 0.34625 & 0.72498 & 0.18447 & 0.24127 \\
\hline $1 \_6$ & 0.40195 & 0.2474 & 0.71882 & 0.26314 & 0.15468 \\
\hline $1 \_8$ & 0.32793 & 0.38311 & 0.7144 & 0.18053 & 0.26881 \\
\hline 1_9 & 0.37086 & 0.36444 & 0.70778 & 0.1554 & 0.25844 \\
\hline $1 \_7$ & 0.35451 & 0.36883 & 0.69342 & 0.17494 & 0.25636 \\
\hline $1 \_10$ & 0.4566 & 0.252 & 0.67771 & 0.25729 & 0.19304 \\
\hline $1 \_11$ & 0.34758 & 0.33898 & 0.66868 & 0.23988 & 0.23401 \\
\hline 1_5 & 0.38865 & 0.37103 & 0.66342 & 0.19849 & 0.21366 \\
\hline 1_12 & 0.40752 & 0.38166 & 0.61555 & 0.24744 & 0.21448 \\
\hline 1_3 & 0.35443 & 0.53214 & 0.60534 & 0.10024 & 0.06794 \\
\hline $1 \_14$ & 0.47568 & 0.29272 & 0.56127 & 0.36502 & 0.07164 \\
\hline 3_14 & 0.19818 & 0.18994 & 0.28854 & 0.7875 & 0.23586 \\
\hline 3_15 & 0.27407 & 0.21858 & 0.31338 & 0.76307 & 0.25297 \\
\hline 3_18 & 0.3644 & 0.36939 & 0.22579 & 0.55551 & 0.04157 \\
\hline $2 \_16$ & 0.34984 & 0.28849 & 0.21602 & 0.15794 & 0.68703 \\
\hline $2 \_15$ & 0.41946 & 0.31635 & 0.20559 & 0.26288 & 0.63546 \\
\hline $2 \_14$ & 0.20271 & 0.41606 & 0.30377 & 0.17465 & 0.58142 \\
\hline 3_2 & 0.25301 & 0.50379 & 0.25662 & 0.16344 & 0.50527 \\
\hline
\end{tabular}

SSQ: the Speech, Spatial and Qualities of Hearing Scale 
타당도 분석

타당도는 측정하고자 하는 값이 얼마나 참값에 가까운지를 나타내는 척도로 본 연구에서는 구성개념 타당도와 준거 타 당도를 이용하여 분석하였다.

\section{구성개념 타당도}

$\mathrm{SSQ}$ 설문지의 구성개념 타당도(construct validity) 분석을 위해 요인 분석(factor analysis)을 수행하였다(Table 3). 주성 분분석을 이용한 factor analysis를 수행하였고, eigenvalue가 1 이상인지를 기준으로 요인(factor) 수를 설정하여 5 개 요인
으로 결정하였고, varimax rotation을 적용하였다. KaiserMeyer-Olkin ratio가 0.97로 sampling adequacy가 높다고 할 수 있었다.

분석 결과 첫 번째 eigenvalue는 33.2로 변수들의 총 분산 중 첫 번째 요인에 의해 설명되는 비율은 $68 \%$ 이며, 두 번째 요인에 의해 설명되는 비율은 $4.2 \%$ (eigenvalue $=2.1$ ), 세 번째 요인에 의해 설명되는 비율은 $3.7 \%$ (eigenvalue=1.8), 네 번째 요인에 의해 설명되는 비율은 $2.6 \%$ (eigenvalue=1.3), 다섯 번 째 요인에 의해 설명되는 비율은 2.1\%(eigenvalue=1.02)였으며 5 개의 요인에 의해 설명되는 누적 설명 비율은 약 $80.4 \%$ 였다.

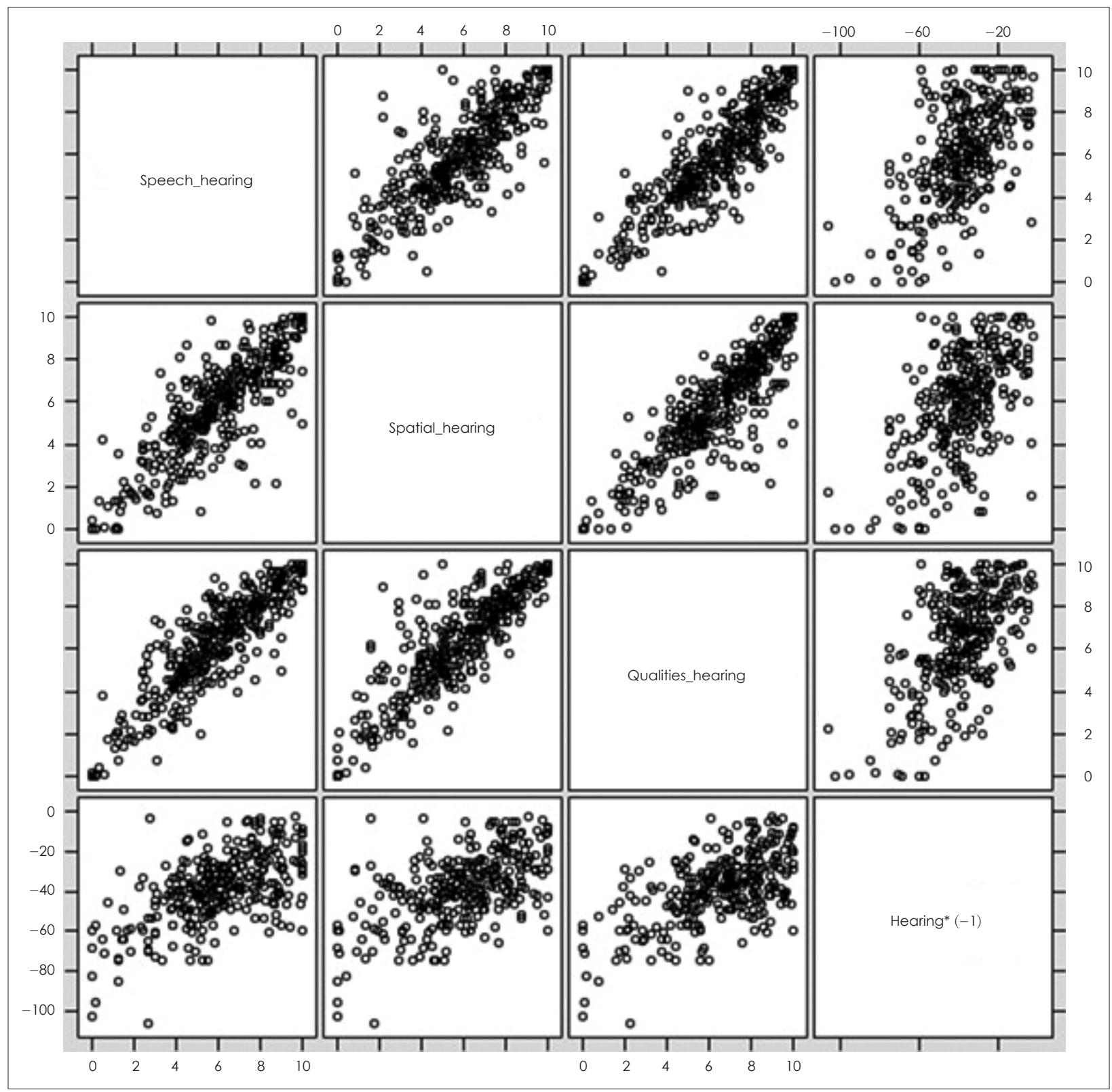

Fig. 1. Scatter plots: each part of SSQ plotted against hearing* $(-1)$. Correlation was made based on hearing* $(-1)$ bacause small value in hearing means better hearing. SSQ: the Speech, Spatial and Qualities of Hearing Scale. 
회전된 성분 행렬의 요인 적재 값을 제시하였고(Table 3), 요 인 적재 값은 해당 문항과 해당 요인 사이의 상관계수를 나 타내며 요인 적재 값 0.4 기준으로 23항목이 제 1 요인에 적재 되었고, 22항목이 제2요인에 적재되었으며, 18항목이 제3요인 에 적재되었다. 제4요인과 제5요인에는 각각 4항목씩 적재되 었다.

\section{준거 타당도}

$\mathrm{SSQ}$ 설문지의 criterion validity 평가를 위해 순음청력검사 결과(gold standard)와 3개의 파트 간 Spearman correlation 을 산출하였고, 각 파트와 청력 간 산점도를 그려 분포를 확인 하였다(Fig. 1). Speech hearing 파트와 청력의 상관계수는 0.55, spatial hearing 파트와 청력의 상관계수는 0.53, qualities of hearing 파트와 청력의 상관계수는 0.53 으로 추정되었다.

\section{고 찰}

본 연구에서, 번역과 역 변역 그리고 절충을 통해 만들어진 한국어판 SSQ는 청취에 어려움이 있는 환자들을 대상으로 한 신뢰도 연구에서, 매우 높은 내적 일치도(Cronbach's $\alpha=0.99$ ) 를 보였으며, 설문의 각 파트 간에 상관계수 0.8 이상의 강한 양의 상관관계를 보여 매우 높은 신뢰도의 설문지임을 확인 할 수 있었다. 또한 타당도 면에서는 구성개념 타당도의 요인 분석에서 요인에 의해 설명되는 비율이 $80 \%$ 이상으로 높은 설 명 비율을 보이고, 순음청력검사 결과와도 각 파트가 양의 상 관관계를 보임으로써 $\mathrm{K}-\mathrm{SSQ}$ 가 충분한 타당도를 지닌 설문 지임을 판단할 수 있었다.

최근 들어 일측성 난청(single sided deafness)의 치료에 대 한 관심이 높아지고 있다. 일측성 난청은 과거에는 적극적인 치료의 대상이 되지 않았지만, 양이 청의 중요성이 강조되면 서 점차 치료의 대상이 되고 있다. ${ }^{12,13)}$ 또한 인공와우 이식, 골 전도 보청기 등 다양한 청각재활방법이 널리 사용되면서 단 순한 청력 개선 효과뿐 아니라, 실제 일상생활에서 청취에 얼 마나 불편함을 느끼는지에 대해서도 평가를 할 수 있는 검사 에 대한 요구가 커지고 있다. SSQ는 개발 당시부터 이러한 목 적을 염두에 두고 고안되었으며, ${ }^{14)}$ 특히 말 인지력과 소리 방 향성, 청취의 질 영역에 대해 최적화된 설문 문항으로 청취에 관한 삶의 질을 평가하고자 하는 최근의 추세에도 부합하는 설문지이다. 이러한 장점으로 $\mathrm{SSQ}$ 는 프랑스어, 러시아어 등으 로 번역되어 검증 과정을 거쳤고, 영어권을 포함한 각 문화권 에서 널리 사용되어 왔다. ${ }^{15,16)}$ 또한 49 개의 문항으로 된 원본 $\mathrm{SSQ}$ 를 적용하기 쉽게 12문항으로 단순화한 SSQ12, 인공와우 를 받는 환자에게 특화된 $\mathrm{SSQ}$ 등 다양한 목적에 따라 $\mathrm{SSQ}$
를 변형하여 사용되고 있다. ${ }^{17)}$ 이러한 국내, 국제적인 추세와 필 요에 따라 한국어판 $\mathrm{SSQ}$ 의 번역 및 검증의 필요성이 대두되 었다. 설문지의 번역이란 것이 단순한 번역 작업이 아니라, 각 언어 및 문화권의 특성을 고려해서 이루어져야 하는 것이기에 대표성을 가진 대한청각학회 산하 설문지 번역위원회에서 주 관하여 번역 작업을 하게 되었다.

본 연구에서 한국어판 설문지의 신뢰도와 타당도 검증을 위한 조사는 전국의 14 개 대학병원에서 시행되었다. 한 병원 에서 시행하였을 경우 그 병원의 환자군 특성에 따라 연구가 영향을 받을 수 있는 우려가 있어, 인구 구성 및 농촌 도시 등 지역적 특성을 고려하여 대상 병원을 결정함으로써 최대한 편향되지 않은 결과를 산출하도록 하였다. 다만 대상 병원이 모두 대학병원인 점은 이 연구의 제한점이 될 수 있겠으나, 본 연구의 목적인 설문지의 신뢰도 및 타당도 검증에는 큰 영향을 주지 않을 것으로 생각하였다.

저자들은 한국어판 $\mathrm{SSQ}$ 를 완성하여 신뢰도 및 타당도를 검증하고 보고하며, 향후 양이 청에 대한 평가 및 청취의 질 관련 연구, 보청기 및 인공와우 사용 후 평가에 관한 연구에 서 공신력 있는 한국어판 $\mathrm{SSQ}$ 설문지가 널리 사용되기를 기 대한다.

\section{Acknowledgments}

We thank Medical Research Collaborating Center of Seoul National University Hospital for statistical analysis. We also would like to thank professors Jae-Jun Song of Korea University, Jae Young Choi of Yonsei University, Sung-Wook Jeong of Dong-A University, and Hyong Ho Cho of Chonnam National University for their assistance in recruiting subjects and conducting survey.

\section{REFERENCES}

1) Gatehouse S, Noble W. The Speech, Spatial and Qualities of Hearing Scale (SSQ). Int J Audiol 2004;43(2):85-99.

2) Zhang J, Tyler R, Ji H, Dunn C, Wang N, Hansen M, et al. Speech, Spatial and Qualities of Hearing Scale (SSQ) and Spatial Hearing Questionnaire (SHQ) changes over time in adults with simultaneous cochlear implants. Am J Audiol 2015;24(3):384-97.

3) Nelissen RC, Mylanus EA, Cremers CW, Hol MK, Snik AF. Longterm compliance and satisfaction with percutaneous bone conduction devices in patients with congenital unilateral conductive hearing loss. Otol Neurotol 2015;36(5):826-33.

4) Kim YJ, Roh J, Lee JJ, Hong SA, Lim HJ, Park HY, et al. Functional listening performance of children with sequential bilateral cochlear implantation in daily life. Korean J Otorhinolaryngol-Head Neck Surg 2015;58(7):463-8.

5) Moulin A, Pauzie A, Richard C. Validation of a French translation of the Speech, Spatial, and Qualities of Hearing Scale (SSQ) and comparison with other language versions. Int J Audiol 2015;54(12): 889-98.

6) Tufatulin GSh, Artyushkin SA. [Validation of the Russian language version of the SSQ questionnaire]. Vestn Otorinolaringol 2016;81(2): 17-22.

7) Galvin KL, Noble W. Adaptation of the Speech, Spatial, and Qualities of Hearing Scale for use with children, parents, and teachers. Cochlear 
Implants Int 2013;14(3):135-41.

8) Byun JY, Cho YS, Chu H, Park SN, Han GC, Cheon BC, et al. Standardization for a Korean version of chronic ear survey: translation and verification of validity and reliability. Korean J OtorhinolaryngolHead Neck Surg 2011;54(11):755-60.

9) Park SN, Han GC, Cho YS, Byun JY, Shin JE, Chu HS, et al. Standardization for a Korean version of Hearing Handicap Inventory for the Elderly. Korean J Otorhinolaryngol-Head Neck Surg 2011;54 (12):828-34.

10) Chu H, Cho YS, Park SN, Byun JY, Shin JE, Han GC, et al. Standardization for a Korean adaptation of the International Outcome Inventory for Hearing Aids: study of validity and reliability. Korean J Otorhinolaryngol-Head Neck Surg 2012;55(1):20-5.

11) Wikipedia. Cronbach's alpha [cited 2016 Aug 26]. Available from: https://en.wikipedia.org/wiki/Cronbach\%27s_alpha.

12) Schwartz SR, Kobylk D. Outcomes of Bone Anchored Hearing Aids (BAHA) for single sided deafness in nontraditional candidates. Otol Neurotol 2016;37(10):1608-13.
13) Rahne T, Plontke SK. Functional result after cochlear implantation in children and adults with single-sided deafness. Otol Neurotol 2016;37(9):e332-40.

14) Noble W, Gatehouse S. Interaural asymmetry of hearing loss, Speech, Spatial and Qualities of Hearing Scale (SSQ) disabilities, and handicap. Int J Audiol 2004;43(2):100-14.

15) Sladen DP, Carlson ML, Dowling BP, Olund AP, Teece K, DeJong $\mathrm{MD}$, et al. Early outcomes after cochlear implantation for adults and children with unilateral hearing loss. Laryngoscope 2017;127(7): 1683-8.

16) Eberhard KE, Olsen SØ, Miyazaki H, Bille M, Caye-Thomasen P. Objective and subjective outcome of a new transcutaneous bone conduction hearing device: half-year follow-up of the first 12 Nordic implantations. Otol Neurotol 2016;37(3):267-75.

17) Noble W, Jensen NS, Naylor G, Bhullar N, Akeroyd MA. A short form of the Speech, Spatial and Qualities of Hearing Scale suitable for clinical use: the SSQ12. Int J Audiol 2013;52(6):409-12. 


\title{
$\square$ Appendix
}

\section{The Speech, Spatial and Qualities of Hearing Scale (SSQ)}

언어 공간 음질 청취 평가

\author{
고유 번호: \\ 조사 일자: \\ 조사 병원: \\ 성 명: \\ 성별/나이: \\ 병록 번호:
}

본 설문지는 다양한 상황에서 귀하의 청력 및 청취 능력을 알아보기 위한 것입니다.

설문은 전체 49 개의 문항으로 구성되어 있으며, 작성에는 약 10 분 정도 소요될 것입니다.

설문 문항 중 이해되지 않거나 모르는 문항이 있다면 검사자에게 질문하여 주시길 바랍니다.

귀하께서 성심성의껏 답해주신 본 자료는 귀하의 난청 진단 및 치료 연구에 활용되며 의학 통계적 목적 이외에는 절대 사용하지 않습니다. 


\section{대한청각학회}

\section{다음 중 한 가지에 표시해 주세요.}

나는 보청기를 사용하지 않는다.

왼쪽 귀에 보청기를 사용 중이다.

오른쪽 귀에 보청기를 사용 중이다.

양쪽 귀에 보청기를 사용 중이다.

만약 보청기를 사용하고 있다면 얼마 동안 사용하였습니까?

(만약 양쪽에 보청기를 사용하고 있으나, 그 기간이 각각 다를 경우 나누어서 기입해 주시기 바랍니다.)

년

개월

주

질문에 답하는 요령: 각각의 질문에 대해 0 10까지 표기되어 있는 숫자 눈금에 'X'로 표시해 주시기 바랍니다. 10에 표 시하는 것은 '귀하는 각 질문에 묘사된 상황에서 완벽히 수행하거나 경험할 수 있음을 의미하며, 0 에 표시하는 것은 '묘 사된 상황을 전혀 수행하거나 경험하지 못함'을 의미합니다.

예를 들어, 1 번 문항은 $\mathrm{TV}$ 를 켜놓은 상태에서 동시에 다른 사람과 대화를 하는 상황에 대한 질문입니다. 귀하가 충분 히 수행할 수 있다면, 눈금의 오른쪽 끝을 향해 표시하고, 대화의 절반 정도를 알아들을 수 있었다면 눈금의 중간 정도 에 표시해 주시면 됩니다. 
모든 질문들은 귀하의 일상생활 경험과 관련 있으리라 기대하지만, 만약 질문이 귀하에게 적용되지 않는 상황을 묘사 한다면, '해당 없음'에 표시해 주시기 바랍니다. 또한 왜 귀하에게 해당되지 않는지 질문 옆에 적어 주십시오.

\section{(Part 1: 언어적 청취 평가)}

1. 귀하는 한 사람과 말하고 있고 같은 방에 TV가 켜져 있습니다. TV 소리를 줄이지 않고 상대방이 말하는 것을 알아들을 수 있습니까?

2. 귀하는 카페트가 깔린 조용한 방에서 한 사람과 대화 하고 있습니다. 그 사람이 말하는 것을 알아들을 수 있 습니까?

3. 귀하를 포함하여 5 명의 사람들과 탁자에 둘러앉아 있 고, 주변은 조용합니다. 모두를 볼 수 있는 상황에서 귀 하는 대화를 따라갈 수 있습니까?

4. 귀하를 포함하여 5 명의 사람들과 붐비는 식당에 있습 니다. 모두를 볼 수 있는 상황에서 귀하는 대화를 따라 갈 수 있습니까?

5. 귀하는 한 사람과 대화하고 있고, 환풍기나 물이 흐르 는 소리 같은 지속적인 배경 소음이 있습니다. 귀하는 상 대방이 말하는 것을 알아들을 수 있습니까?

6. 귀하를 포함하여 5 명의 사람들과 붐비는 식당에 있습 니다. 모두를 볼 수는 없을 때 귀하는 대화를 따라갈 수 있습니까?

7. 귀하는 교회나 서울역 건물 같은, 울림이 많은 장소에 서 누군가와 대화하고 있습니다. 귀하는 상대방이 말하 는 것을 알아들을 수 있습니까?

8. 귀하는 어떤 사람과 대화 중에 그 사람과 같은 굵기 (톤)의 목소리를 가진 다른 사람이 말을 해도 상대방과 대화를 나눌 수 있습니까?

9. 귀하는 어떤 사람과 대화 중에 그 사람과 다른 굵기 (톤)의 목소리를 가진 사람이 말을 해도 상대방과 대화 를 나눌 수 있습니까?
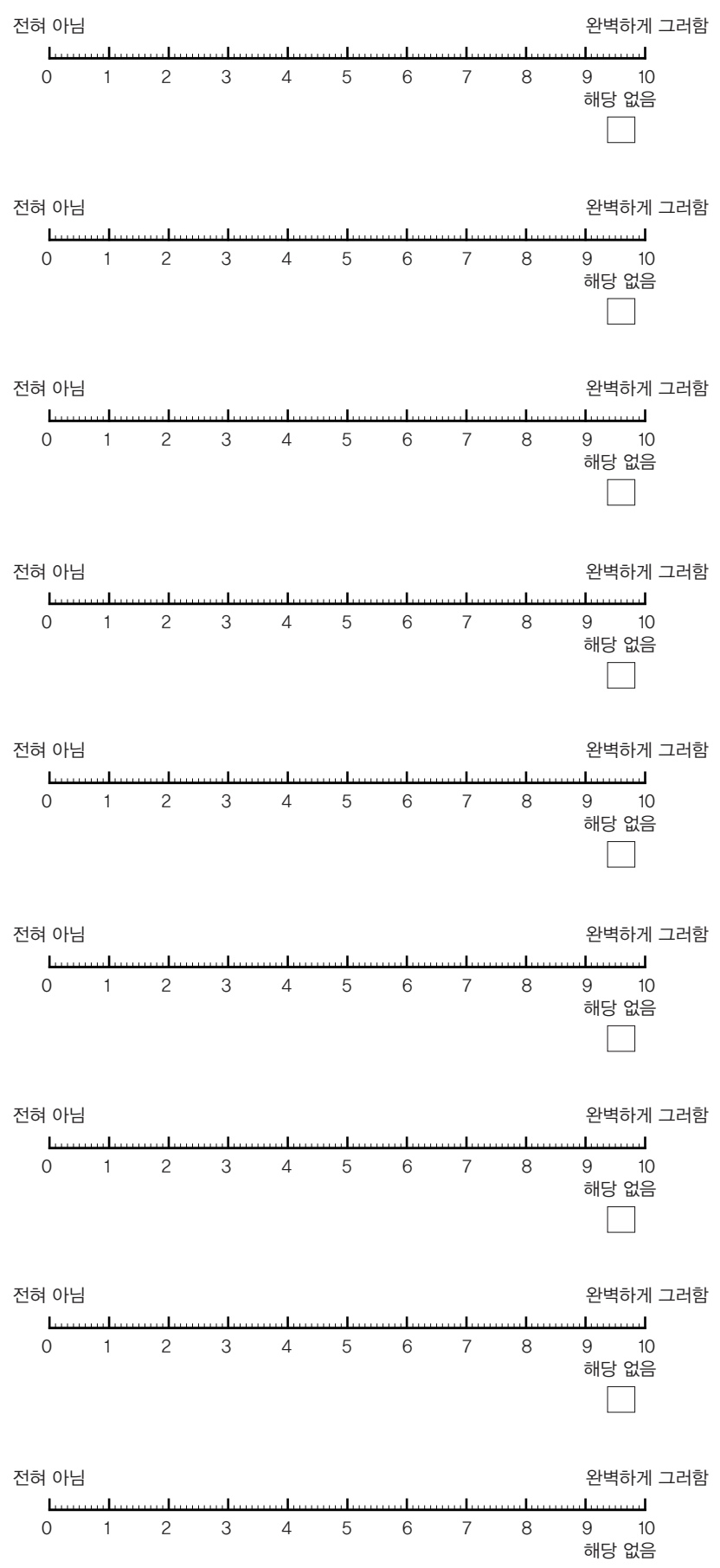
10. 귀하는 TV 뉴스를 보면서 동시에 누군가의 말을 듣 고 있습니다. 귀하는 양측의 말을 모두 알아들을 수 있습 니까?

11. 귀하는 많은 사람이 말하고 있는 방에서 한 사람과 대화 중입니다. 귀하는 상대방이 말하는 것을 알아들을 수 있습니까?

12. 귀하는 그룹 안에서 서로 돌아가며 대화하고 있습니 다. 새로운 사람이 말을 할 때 시작부터 놓치지 않고 쉽 게 따라갈 수 있습니까?

13. 귀하는 전화로 쉽게 대화를 할 수 있습니까?

14. 귀하는 전화로 누군가의 말을 듣고 있고 옆에 있는 사람이 말을 걸기 시작합니다. 귀하는 양측의 말을 모두 알아들을 수 있습니까?

\section{(Part 2: 공간적 청취 평가)}

1. 귀하는 익숙하지 않은 야외에 있습니다. 누군가 기계 로 잔디 깎는 소리가 들리지만 그 모습을 볼 수 없습니 다. 귀하는 소리가 어디서 나는지 바로 알 수 있습니까?

2. 귀하는 여러 사람과 탁자에 둘러앉아 있거나 모임을 하 고 있고 모두를 볼 수는 없습니다. 누군가 말하기 시작하 자 마자 귀하는 그 사람이 어디 있는지 알 수 있습니까?

3. 귀하는 두 사람 사이에 앉아 있습니다. 그들 중 한 사 람이 말하기 시작할 때 귀하는 쳐다보지 않고 그 사람이 오른쪽에 있는지 왼쪽에 있는지 바로 알 수 있습니까?

4. 귀하는 익숙하지 않은 집에 있습니다. 조용한 가운데 문이 쾅 닫히는 소리를 들으면 귀하는 그 소리가 어디서 났는지 바로 알 수 있습니까?

5. 귀하는 건물의 위아래 층 사이 계단에 있습니다. 다른 층에서 나는 소리들을 듣는다면 귀하는 그 소리가 어디 서 나는지 쉽게 알 수 있습니까?
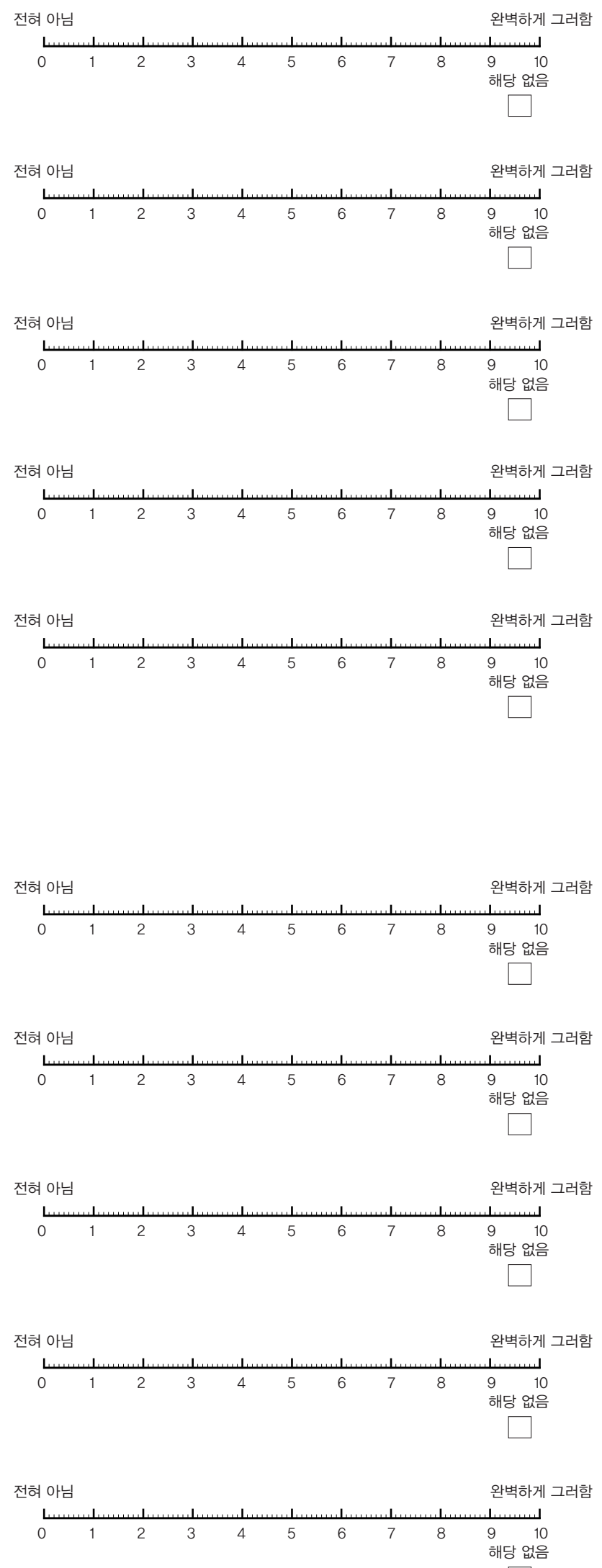
6. 귀하는 밖에 있습니다. 개가 크게 짖고 있다면 귀하는 쳐다보지 않고 그 개가 어디 있는지 즉시 알 수 있습니까?

7. 귀하는 붐비는 거리의 보행로에 서 있습니다. 귀하는 버 스나 트럭이 어느 방향에서 오는지 보기 전에 듣고 바로 알 수 있습니까?

8. 귀하는 거리에서 누군가의 목소리나 발소리로 그 사람 이 얼마나 멀리 떨어져 있는지 알 수 있습니까?

9. 귀하는 버스나 트럭의 소리로 그것들이 얼마나 멀리 떨어져 있는지 판단할 수 있습니까?

10. 귀하는 버스나 트럭의 소리만 듣고 어느 방향으로 이 동 중인지 알 수 있습니까? (예: 귀하의 왼쪽에서 오른쪽 으로 또는 오른쪽에서 왼쪽으로)

11. 귀하는 어떤 사람의 목소리나 발소리만 듣고 그 사람 이 어느 방향으로 이동 중인지 알 수 있습니까? (예: 귀하 의 왼쪽에서 오른쪽으로 또는 오른쪽에서 왼쪽으로)

12. 귀하는 목소리나 발소리로 그 사람이 귀하를 향해서 다가오는지 멀어져 가는지를 알 수 있습니까?

13. 귀하는 소리로 버스나 트럭이 귀하를 향해서 다가오 는지 멀어져 가는지를 알 수 있습니까?

14. 귀하는 소리를 들을 때 명확히 외부에서 들린다기보 다 귀하의 머릿속에서 맴도는 것처럼 들립니까?

15. 귀하가 볼 수 없고 들을 수만 있는 사람 또는 물건의 소리를 듣고 실제로 보게 되면 예상했던 것보다 더 가까 이 있습니까?

16. 귀하가 볼 수 없고 들을 수만 있는 사람 또는 물건의 소리를 듣고 실제로 보게 되면 예상했던 것보다 더 멀리 있습니까?
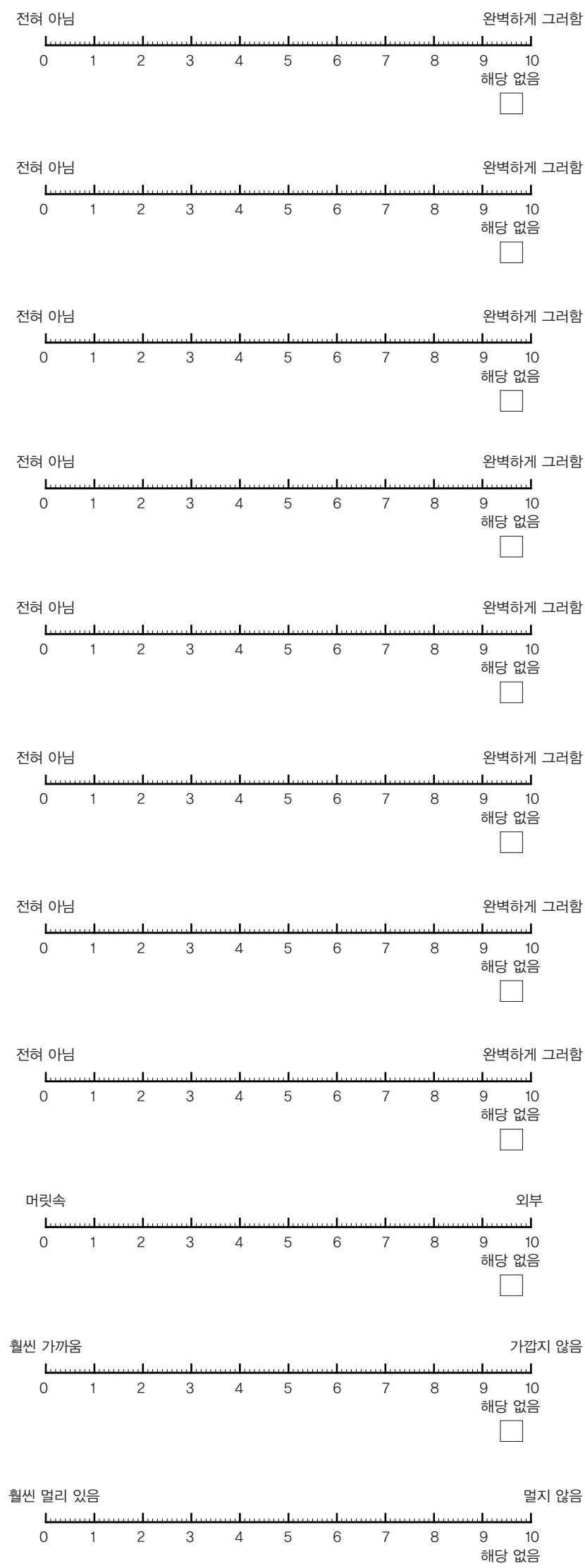
17. 귀하는 소리가 나는 곳이라고 예상되는 위치를 정 확히 예측할 수 있습니까?

\section{(Part 3: 음질 청취 평가)}

1. 귀하는 두 가지 소리를 한꺼번에 들을 때 각각의 소리 를 구분할 수 있습니까? (예: 라디오 소리와 물 붓는 소리 가 동시에 들릴 때)

2. 귀하는 두 가지 이상의 소리를 동시에 들을 때 하나의 합쳐진 소리로 들립니까?

3. 귀하가 라디오에서 음악이 흘러나오는 방에서 누군가 와 말하고 있을 때 그 사람의 목소리를 음악과 구별해서 들을 수 있습니까?

4. 귀하는 사람들을 각자의 목소리로 쉽게 알 수 있습 니까?

5. 귀하는 친숙한 음악 작품들을 서로 쉽게 구별할 수 있 습니까?

6. 귀하는 소리들 간의 차이를 구분할 수 있습니까? (예: 자동차와 버스 소리, 냄비에서 물 끓는 소리와 프라이팬 에서 음식을 요리하는 소리)

7. 귀하는 음악을 들을 때 어떤 악기로 연주하는지 알아 들을 수 있습니까?

8. 귀하는 음악을 들을 때 분명하고 자연스럽게 들립니 까?

9. 귀하는 흔히 접하는 일상생활의 소리들이 분명하게 들 립니까?
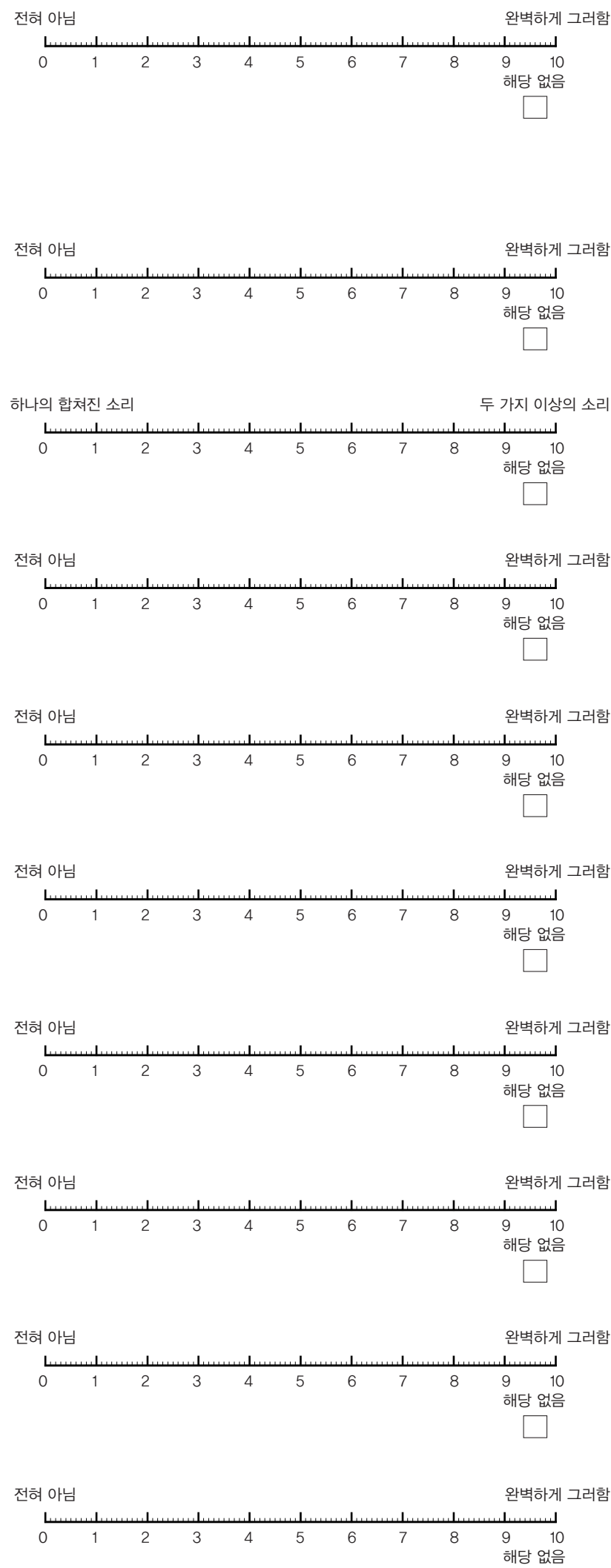
10. 귀하는 다른 사람들의 목소리가 분명하고 자연스럽 게 들립니까?

11. 귀하가 듣는 일상생활 소리들이 부자연스럽습니까?

12. 귀하 본인의 목소리가 자연스럽게 들립니까?

13. 귀하는 사람들의 목소리로 그들의 기분을 쉽게 판단 할 수 있습니까?

14. 귀하는 누군가의 말을 듣거나 무엇인가를 들을 때 굉 장히 집중해야만 합니까?

15. 귀하는 다른 사람들과 대화할 때 알아듣기 위해서 많은 노력을 기울여야 합니까?

16. 귀하가 운전할 때 옆 사람이 말하는 것을 쉽게 알아 들을 수 있습니까?

17. 귀하가 조수석에 앉아 있을 때 운전자가 말하는 것을 쉽게 알아들을 수 있습니까?

18. 귀하는 무엇인가를 들으려고 애쓸 때 그 소리 외에 다른 소리들은 쉽게 무시할 수 있습니까?

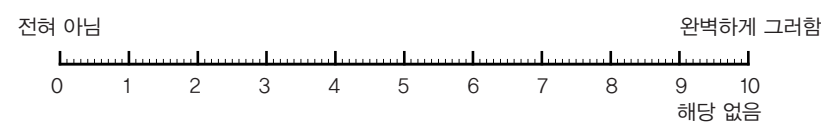

자연스럽지 않음

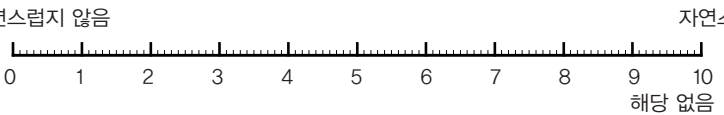

자연스러움
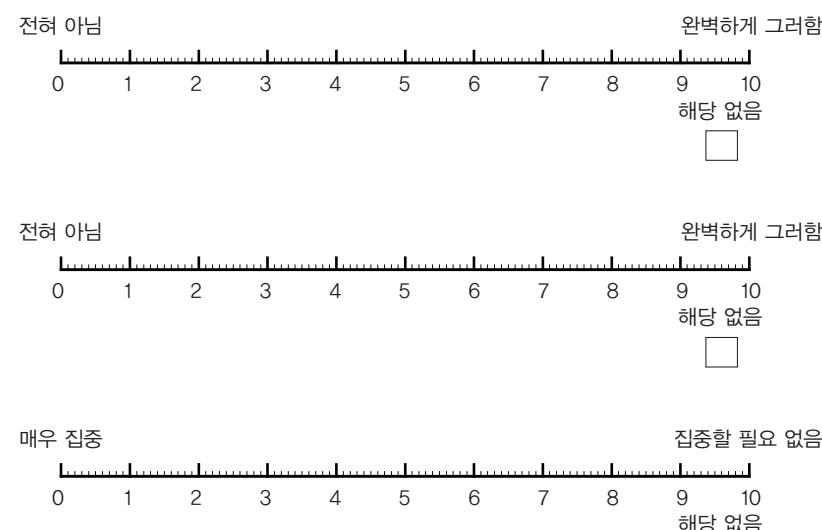

많은 노력을 기울여야 함 노력할 필요 없음
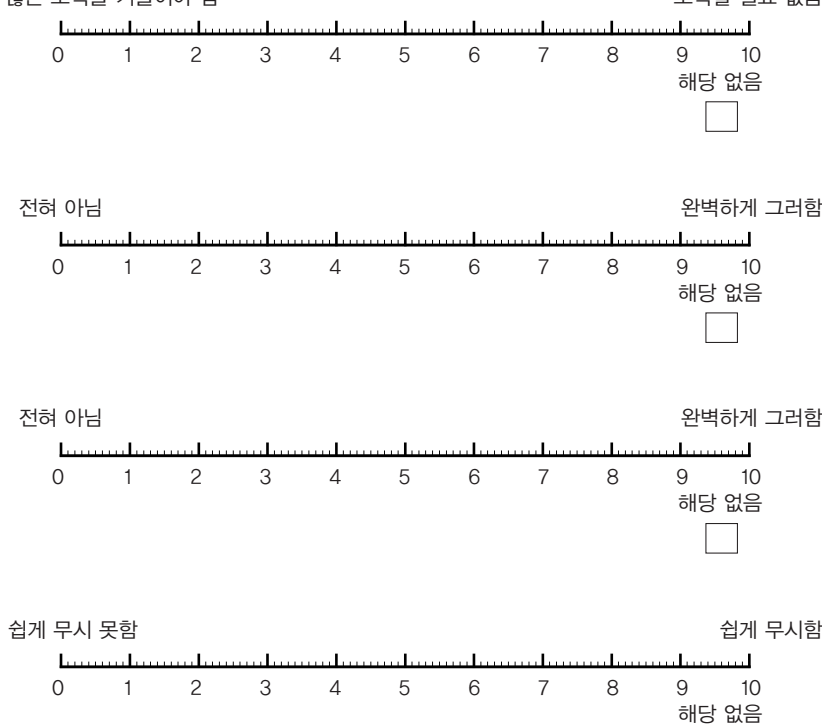

응답하여 주셔서 대단히 감사합니다.

저희 학회에서는 설문에 응하신 귀하의 비밀을 보장하고 있습니다.

본 설문지는 귀하의 난청 진단과 치료 연구에 참고자료로 활용할 뿐 의학 통계적 목적 이외에는 절대 사용하지 않음 을 다시 한번 강조해 드립니다. 
Korean J Otorhinolaryngol-Head Neck Surg I 2017;60(6):279-94

조사자 작성 사항

1. 청력검사 소견

\begin{tabular}{|l|l|l|l|l|l|}
\hline \multicolumn{1}{|c|}{$\mathrm{Hz}$} & 500 & 1000 & 2000 & 3000 & 4000 \\
\hline 기도 (우) & & & & & \\
\hline Aided (우) & & & & & \\
\hline 기도 (좌) & & & & & \\
\hline Aided (좌) & & & & & \\
\hline
\end{tabular}

어음 분별력

우측:

$\%$

$\mathrm{dB}$ 좌측:

$\%$

$\mathrm{dB}$

보청기 착용 어음 분별력

우측:

$\%$

$\mathrm{dB}$ 좌측:

$\% \quad \mathrm{~dB}$ 